\title{
Contexto rural e a reabilitação profissional em uma região do Vale do Ribeira
}

\author{
Rural context and professional rehabilitation in a region of the Ribeira \\ Valley
}

Camilla de Paula Zavarizzi', José Martim Marques Simas', Luiza Fabro dos Santos'1, Maria do Carmo Baracho de Alencar ${ }^{\mathbf{1}}$

DOI: $10.1590 / 0103-1104201912306$

RESUMO Objetivo: Investigar o perfil sociodemográfico, de trabalho e saúde, de trabalhadores de uma região de Registro (SP), localizada no Vale do Ribeira, e identificar as barreiras e os facilitadores no processo de reabilitação profissional do Instituto Nacional de Seguridade Social (INSS), de segurados dessa região. Métodos: Duas etapas: (1) Foi obtida uma listagem de trabalhadores junto à Estratégia Saúde da Família de bairros rurais do município de Registro (SP), e aplicou-se, sob forma de entrevista, um questionário com dados sociodemográficos, de trabalho e saúde. (2) Posteriormente, foram identificados dois profissionais de referência do INSS, que atuavam na sede dessa região e, ainda, foram realizadas entrevistas individuais para análise de conteúdo temático. Resultados: Com relação ao perfil dos sujeitos, a maioria dos trabalhadores atuava em plantações de banana, morava nas fazendas, tinha baixa escolaridade; todos refeririam sintomas osteomusculares, entre outros. Nas entrevistas com os profissionais de referência do INSS, foi possível observar, entre as principais barreiras para a reabilitação profissional encontradas: o perfil dos segurados da região rural com baixa escolaridade, com dificuldades em transporte, poucos cursos ofertados, e a avaliação do médico perito com base no modelo biomédico, com sofrimento e injustiças. Entre os facilitadores: o acolhimento dos profissionais de referência assistentes sociais, o vínculo estabelecido e a empatia. Conclusão: Há necessidade de políticas públicas que possam garantir os direitos dos trabalhadores e promovam melhorias no modelo atual de reabilitação profissional.

PALAVRAS-CHAVE Saúde do trabalhador. Saúde da população rural. Reabilitação.

ABSTRACT Aim: To investigate the sociodemographic profile, of work and health, of workers from a region of Registro (SP), locate in Ribeira Valley, and to identify the barriers and facilitators in the professional rehabilitation process of the National Institute of Social Security (INSS), of insured persons workers of this region. Methods: Two steps: (1) A list of workers was obtained from the Family Health Strategy of rural neighborhoods in the city of Registro (SP), and a questionnaire with sociodemographic data, of work and health, was applied, under the form of an interview. (2) Subsequently, two reference professionals of the INSS, who worked at the headquarters of this region were identified and, in addition, individual interviews were conducted to analyze thematic content. Results: Regarding the profile of the subjects, most workers worked on banana plantations, lived on farms, had low schooling; all reported musculoskeletal symptoms, among others. In interviews with reference professionals of the INSS, it was possible to observe, among the main barriers found to professional rehabilitation: the profile of insured rural people with low schooling, with difficulties in transportation, few courses offered, and the evaluation of the medical expert based on the biomedical model, with suffering and injustice. Among the facilitators: the welcome of the social workers reference professionals, the bond established

1 Universidade Federal de São Paulo (Unifesp) Santos (SP), Brasil. milla_zavarizzi@hotmail. com and the empathy. Conclusion: There is a need for public policies that can guarantee the rights of workers and promote improvements in the current model of professional rehabilitation.

KEYWORDS Occupational health. Rural health. Rehabilitation. 


\section{Introdução}

Os trabalhadores rurais vivem, em geral, um intenso processo de desproteção social, pois muitas vezes exercem atividades laborais na informalidade, e em condições precárias de moradia e trabalho. E quando ficam adoecidos e incapacitados para exercerem atividades laborais, também sofrem com as barreiras existentes para o retorno ao trabalho através do Programa de Reabilitação Profissional'. No contexto rural, existem diversos fatores distintos em relação a esta população, que, de uma forma geral, apresenta baixa escolaridade e baixos rendimentos financeiros, dificuldades no acesso aos bens e serviços sociais, de saúde e comércio ${ }^{2}$. Cabe ressaltar que a população rural é maior do que a urbana em aproximadamente $30 \%$ dos municípios brasileiros, chegando a $40 \%$ nos municípios com menos de 20 mil habitantes, e estima-se que, no Brasil, existam cerca de 30 milhões de trabalhadores rurais, demarcando em torno de $20 \%$ da população economicamente ativa ${ }^{3}$. Porém, somente após 1988, os trabalhadores rurais (homens e mulheres) passaram a ter os mesmos direitos dos trabalhadores urbanos ${ }^{4}$. Assim, o trabalhador rural também tem o direito de exercer suas funções em um ambiente sadio e seguro, sendo de responsabilidade do empregador tomar as medidas necessárias no intuito de diminuir os riscos à saúde e à segurança desse trabalhador ${ }^{5}$.

As alterações no mundo do trabalho impuseram uma forma diferenciada de vida à população do campo, influenciando no agravo do processo de saúde-doença e nas cargas de trabalho ${ }^{6}$. Na agricultura, encontram-se ocupações perigosas para os trabalhadores, não somente pela utilização de ferramentas, máquinas e agrotóxicos, mas especialmente pela exigência de grandes esforços físicos em geral no desempenho das atividades ${ }^{7}$. Ainda, o trabalho agrícola apresenta altas taxas de morte acidental, de ferimentos e de doenças relacionadas ao trabalho ${ }^{8}$. Trabalhadores rurais, com menor poder aquisitivo, dispõem de parcos recursos para organizar seus processos de trabalho e poucos contam com as tecnologias que facilitam ou substituem o trabalho manual'. Sendo assim, jornadas exaustivas de trabalho, carregamento de peso excessivo, posturas inadequadas e outras características ergonômicas acarretam-lhes o surgimento de distúrbios osteomusculares, principalmente problemas de coluna lombar ${ }^{10}$. Muitas destas doenças levam ao afastamento das atividades de trabalho, sendo alguns trabalhadores encaminhados ao Programa de Reabilitação Profissional (PRP) do Instituto Nacional do Seguro Social (INSS).

Oficialmente, o PRP é um serviço prestado pelo INSS aos contribuintes da Previdência Social (PS), previsto na Lei $n^{\circ} 8.213 / 91$. É uma assistência (re)educativa e de (re)adaptação profissional, que visa proporcionar aos trabalhadores segurados, incapacitados parcial ou totalmente para o trabalho, e de caráter obrigatório, os meios indicados para o reingresso no mercado de trabalho e no contexto em que vivem ${ }^{11}$. O PRP foi criado em resposta ao crescente número de pessoas incapacitadas para o trabalho em decorrência de acidentes de trabalho e doenças ocupacionais durante o governo Vargas, época do regime ditatorial, e hoje, pode ser entendido como um subprograma de perícias médicas, o qual possui um caráter assistencialista sob a lógica compensatória ${ }^{12}$.

Sendo assim, a prestação dos serviços de Reabilitação Profissional (RP) articulada aos sistemas de PS tem um duplo papel: por um lado, corresponde a formas de intervenção para a redução e superação das desvantagens produzidas por incapacidades, e, por outro, a estratégias de regulação econômica dos sistemas com a finalidade de reduzir o tempo de concessão de benefícios previdenciários ${ }^{13}$. $\mathrm{O}$ PRP é uma opção para os trabalhadores, em sua maioria, contribuintes da PS, em gozo de auxílio-doença acidentário ou previdenciário, que se encontram incapacitados para exercerem seus trabalhos de origem, e cujas incapacidades e restrições laborais estejam estabilizadas e sejam de longa duração ${ }^{14}$. Os procedimentos que orientam os trabalhadores do INSS envolvidos com a RP estão fundamentados no documento 
'Manual Técnico de Procedimentos da Área de Reabilitação Profissional', atualizado em $2018^{15}$.

O encaminhamento ao PRP é realizado pela perícia médica do INSS, e o atendimento é feito pela equipe de RP, a qual deve ser, preferencialmente, multidisciplinar, composta por peritos médicos do INSS e analistas do seguro social com formação nas áreas de serviço social, psicologia, terapia ocupacional, sociologia, fisioterapia ou áreas afins ao processo, denominados Responsáveis pela Orientação Profissional (ROP) ${ }^{15}$.

Houve, em 2016, uma ampliação do conceito de incapacidade com base no modelo biopsicossocial de saúde, e introduziram-se as abordagens territoriais, porém os esforços para a introdução dessas mudanças não foram capazes de romper com a macropolítica hierárquica e de ordem cultural e histórica do INSS ${ }^{16}$. Na versão do 'Manual Técnico de Procedimentos da área de Reabilitação Profissional' de 2018, voltaram a ser reforçadas as ações de caráter biomédico baseadas em uma lógica de assistência insuficiente e precária ${ }^{16}$. Para Pereira e Nogueira ${ }^{17}$, o PRP é uma 'válvula de escape' que possibilita a saída do segurado do recebimento de benefícios do INSS.

O profissional médico é quem possui a responsabilidade de avaliar a incapacidade para o trabalho, deferir ou indeferir um benefício previdenciário e encaminhar o segurado ao PRP. Sendo assim, a avaliação do médico perito é influenciada por sua formação focada no raciocínio clínico e na realização diagnóstica. Além disto, muitas vezes é baseada também em critérios pessoais e descontextualizados, e não são avaliadas as questões sociopolíticas da incapacidade, uma vez que somente os agravantes físicos são considerados ${ }^{\mathbf{1 4}}$. Neste sentido, um dos desafios a serem vencidos diz respeito à construção de um consenso sobre as concepções de saúde, incapacidade, reabilitação psicossocial e profissional. E esses conceitos devem levar em consideração também o contexto rural de trabalho.

A RP propriamente dita é a reinserção, na empresa de vínculo, em uma nova atividade laborativa. Quando isto não é possível, são oferecidos cursos profissionalizantes custeados pelo INSS ${ }^{18}$. No entanto, em muitos casos, é necessário realizar a elevação de escolaridade para a inclusão em tais cursos. A RP cessa com a emissão de um certificado que indica a função para a qual o reabilitando foi capacitado profissionalmente ${ }^{19}$. E a homologação da reabilitação do segurado, independentemente das condições reais de efetiva reinserção no ambiente de trabalho, fica a cargo da empresa, com pouca interferência do Estado ${ }^{20}$.

O cenário das políticas públicas sociais, no País, vive um momento de incertezas e preocupações diante das medidas e reformas aprovadas no último ano. Para Miranda ${ }^{16}$, os serviços previdenciários - sendo um deles, o PRP - são impactados pelas mudanças societárias decorrentes de reformas políticas, caracterizadas na ênfase em um modelo neoliberal, e por medidas que minimizam o papel do Estado na garantia de direitos e proteção social. Diante da conjuntura política e econômica atual, e desde a década de 1990, o PRP vem sofrendo um crescente processo de sucateamento no Brasil. Com isto, o retorno ao trabalho através do PRP é um desafio complexo para o campo da saúde pública e previdenciária.

O objetivo do presente estudo foi o de investigar o perfil sociodemográfico, de trabalho e saúde, de trabalhadores rurais de uma região de Registro (SP), no Vale do Ribeira, e identificar as barreiras e os facilitadores no processo de RP do INSS, pelas percepções dos profissionais de referência da região.

\section{Métodos}

Trata-se de um estudo realizado em duas etapas. Na primeira etapa, foi obtida uma listagem de trabalhadores rurais do território de abrangência da equipe de Estratégia Saúde da Família (ESF) do Jardim São Paulo, em Registro (SP), que fica situada no Vale do Ribeira. A escolha desses bairros se deu por apresentarem predomínio de atividade 
econômica rural. Além disto, por haver a proximidade de alguns pesquisadores com a equipe ESF local, e pela possibilidade de acesso aos locais de moradia e trabalho. O Vale do Ribeira é uma região compreendida entre as regiões sul do Estado de São Paulo e leste do Estado do Paraná, que compreende 30 municípios. Entre os municípios do Vale do Ribeira, o município de Registro (SP) tem particular importância devido à sua localização geográfica e por ser um relevante polo agrícola e comercial, além de participar de órgãos e serviços estatais e federais, sendo o município denominado 'Capital do Vale do Ribeira'21. Registro (SP) possui cerca de 80 bairros e a sua população foi estimada pelo Instituto Brasileiro de Geografia e Estatística (IBGE) (2018) com 56.249 habitantes, sendo que 48.169 deles viviam na zona urbana e 6.092 na zona rural. Ainda segundo os dados do IBGE (2019), as produções de banana e palmito são evidenciadas.

A partir da listagem obtida, foram realizadas visitas aos locais de trabalho e moradia, acompanhadas, inicialmente, por um agente comunitário de saúde. Nessas visitas, foram aplicados, individualmente e sob forma de entrevista, questionários previamente elaborados, junto aos trabalhadores, contendo dados sociodemográficos, de trabalho e saúde, e itens sobre afastamento do trabalho e vinculações ao PRP. Os questionários foram aplicados após o consentimento voluntário dos sujeitos em participar do estudo. Os critérios de seleção dos sujeitos foram: serem trabalhadores rurais vinculados à ESF Jardim São Paulo e possuírem algum vínculo com a propriedade rural. Não participaram da pesquisa trabalhadores temporários, que prestavam serviços por meio de empresas terceirizadas e que, em geral, não possuíam vínculo ou cadastro junto à $\mathrm{ESF}$, por não residirem no território de abrangência a ela referente. Optou-se, neste estudo, por investigar o perfil sociodemográfico de trabalhadores rurais de uma região do município de Registro (SP) pela impossibilidade (restrição obtida) de contatar os segurados do INSS e vinculados ao PRP.
Para a segunda etapa também foi obtida uma listagem dos profissionais de referência do PRP do INSS vinculados à unidade sede de Santos (SP), através do responsável técnico do setor de RP, com os nomes e contatos telefônicos do município de Registro (SP), no Vale do Ribeira. Identificaram-se, a partir dessa listagem, somente dois profissionais de referência vinculados ao INSS, atuantes no PRP no município. Foram obtidos os dados pessoais e de trabalho desses profissionais de referência na região, e, posteriormente, foram realizadas entrevistas individuais que tiveram uma duração aproximada de 60 minutos. As entrevistas ocorreram no local de trabalho, e foram gravadas e transcritas na íntegra para análise de conteúdo temático ${ }^{\mathbf{2 2}}$. A análise de conteúdo é um conjunto de técnicas de análise das comunicações, que utiliza procedimentos sistemáticos e objetivos de descrição do conteúdo das mensagens, tendo como objeto a fala, isto é, o aspecto individual e atual (em ato) da linguagem ${ }^{22}$. Essas entrevistas ocorreram após agendamentos prévios, através de contato telefônico, em sala reservada, e na sede do INSS em Registro (SP). O estudo foi realizado obedecendo aos princípios éticos da pesquisa com seres humanos, e foi aprovado pelo Comitê de Ética em Pesquisa da Universidade Federal de São Paulo (Unifesp). Número do parecer CAAE (Certificado de Apresentação para Apreciação Ética): 1.510.029

\section{Resultados e discussões}

Na listagem dos bairros rurais adstritos à ESF Jardim São Paulo, obteve-se o registro de 10 propriedades rurais com atividades predominantes de produção de banana. Foram aplicados questionários para 36 trabalhadores, $o$ que representou $95 \%$ dos trabalhadores rurais da bananicultura daquele território. A tabela 1 demonstra alguns dados sociodemográficos, de trabalho e saúde dos trabalhadores da localidade. 


\begin{tabular}{|c|c|c|}
\hline Variáveis $(n=36)$ & Dados & $\%$ \\
\hline \multirow[t]{2}{*}{ Sexo } & Masculino & $94,4 \%$ \\
\hline & Feminino & $5,6 \%$ \\
\hline \multirow[t]{4}{*}{ Faixa etária } & $<20$ anos & $8,3 \%$ \\
\hline & 20 a 29 anos & $27,8 \%$ \\
\hline & 30 a 39 anos & $19,4 \%$ \\
\hline & Acima de 40 anos & $44,5 \%$ \\
\hline \multirow[t]{5}{*}{ Escolaridade } & Nunca foi à escola & $5,6 \%$ \\
\hline & Ensino fundamental incompleto & $50 \%$ \\
\hline & Ensino fundamental completo & $8,3 \%$ \\
\hline & Ensino médio incompleto & $13,9 \%$ \\
\hline & Ensino médio completo & $22,2 \%$ \\
\hline \multirow[t]{2}{*}{ Renda familiar } & 1 a 2 salários mínimos & $71,4 \%$ \\
\hline & 3 a 4 salários mínimos & $28,6 \%$ \\
\hline \multirow[t]{2}{*}{ Tipo de contrato de trabalho } & Registro em carteira/CLT* & $58,3 \%$ \\
\hline & Informal ou autônomo & $41,6 \%$ \\
\hline \multirow[t]{2}{*}{ Tempo de trabalho rural } & Inferior a 10 anos & $18,5 \%$ \\
\hline & Superior a 10 anos & $81,5 \%$ \\
\hline \multirow[t]{2}{*}{ Sintomas osteomusculares no trabalho } & $\operatorname{sim}$ & $90,3 \%$ \\
\hline & Não & $9,7 \%$ \\
\hline \multirow{2}{*}{$\begin{array}{l}\text { Ocorrência anterior de afastamento das atividades de trabalho } \\
\text { pelo INSS }\end{array}$} & Sim & $14,3 \%$ \\
\hline & Não & $85,7 \%$ \\
\hline \multirow[t]{2}{*}{ Tratamentos realizados } & Caseiro/automedicação & $80 \%$ \\
\hline & Ambulatorial/hospitalar & $20 \%$ \\
\hline
\end{tabular}

Fonte: Elaboração própria.

${ }^{*}$ Consolidação das Leis do Trabalho.

Conforme observado, a maioria dos trabalhadores era do sexo masculino, com baixa escolaridade e com renda familiar de um a dois salários mínimos. A baixa escolaridade é comum entre os trabalhadores nas áreas rurais, bem como os baixos salários ${ }^{3}$. Observou-se um percentual elevado de trabalhadores informais e alguns autônomos, demonstrando a desproteção social do trabalhador. Com isso, desigualdades e iniquidades sociais podem ocorrer e gerar sofrimento mental ${ }^{23}$. O tempo de trabalho também foi superior a 10 anos para a maioria e, para alguns, foi superior a 20 anos. Em relação às queixas de saúde, todos apresentaram sintomas osteomusculares, sendo o sintoma doloroso evidenciado em diversas regiões corporais; alguns referiram os sintomas durante a jornada de trabalho. Todos os trabalhadores atuavam com ênfase na bananicultura (que é uma das atividades econômicas prevalentes na região rural) e moravam em casas dos proprietários das fazendas, não pagando aluguel, porém arcando com as despesas da energia elétrica utilizada.

Entre os sujeitos do território da ESF houve poucos afastamentos do trabalho, e nenhum deles havia passado pelo PRP. Vale ressaltar que esse território representa apenas uma região. A maioria optava por tratamentos medicamentosos caseiros/automedicação, 
por dificuldades de acesso aos serviços de saúde, uma vez que poucos tinham carro para locomoção e não havia transporte coletivo no território, no momento do estudo, para o deslocamento até alguma Unidade Básica de Saúde (UBS). O deslocamento comumente ocorria a pé (cerca de $1 \mathrm{~h} 30 \mathrm{~m}$ ) ou de bicicleta, o que era muito penoso em caso de acidentes e/ou doenças, e demonstrava as injustiças e as desproteções sociais existentes. Problemas sociais e de saúde são enfrentados pela população do campo, com dificuldades de acesso aos bens e serviços, principalmente de saúde ${ }^{24}$.

Na segunda etapa, participaram das entrevistas dois ( $\mathrm{n}=02)$ profissionais de referência, que atuavam no município de Registro (SP). Foram-lhes atribuídos nomes fictícios, para preservar o sigilo. Após análise das entrevistas, foram elencadas duas categorias temáticas: 'Barreiras no processo de RP' e 'Facilitadores no processo de RP'.

\section{Barreiras no processo de RP em áreas rurais}

Os depoimentos trouxeram como barreiras as problemáticas em relação à discrepância entre o que o serviço oferecia e o perfil dos segurados da agência. O perfil dos segurados atendidos, segundo os profissionais de referência, era de trabalhadores rurais, que, na maior parte de suas vidas, se dedicaram a trabalhos 'braçais'.

[...] são trabalhadores rurais, trabalhadores de banana, pessoas que trabalhavam carregando excesso de peso, pessoas que trabalhavam em serviços gerais, alguns motoristas de caminhão. Então, basicamente, essas são as pessoas que normalmente são atingidas e que vêm buscar reabilitação. (João).

Na agricultura, os esforços físicos são frequentes no desempenho das atividades ${ }^{25}$. Sendo assim, o esforço físico é uma das características do trabalho braçal, e um dos riscos para o desenvolvimento de doenças osteomusculares $^{26}$. Uma vez lesionados, há receios e dificuldades de se enquadrarem na atividade de trabalho anterior, pelas exigências físicas, gerando medo e insegurança para o retorno ao trabalho. Essa situação era agravada pelo fato de que muitos desses trabalhadores rurais começaram a trabalhar na infância.

[...] começaram a trabalhar desde a infância na roça, com carga, com trabalho pesado, manual, braçal. A grande maioria do que eu atendo aqui, quando eu faço essa pergunta, dos que têm problema na coluna, enfim, tem um vínculo de trabalho infantil. (Marcos).

Muitos começaram a trabalhar na infância, como dito, incentivados pelos pais. E uma das consequências do trabalho infantil é o abandono dos estudos para ajuda no sustento de suas famílias ${ }^{\mathbf{1 4}}$. Com isso, havia uma baixa escolaridade entre os segurados atendidos, impondo desafios para os estímulos à voltar aos estudos. "[...] Aí, o cara tem 40 e tantos anos, quase 50 anos, semianalfabeto, e o cara mora numa cidade rural. Como é que eu vou reabilitar essa pessoa?" (Marcos).

Longos anos fora da escola podem tornar a volta aos estudos algo penoso. De acordo com dados do IBGE (2017), cerca de $15 \%$ dos produtores rurais nunca frequentaram uma escola; $31,3 \%$ possuíam apenas o ensino fundamental; $\mathrm{e}$ apenas $26,4 \%$ concluíram o ensino médio ${ }^{3}$. Cabe ressaltar que muitos trabalhadores começam a ajudar os pais nas atividades de trabalho quando ainda são crianças, e, muitas vezes por necessidades econômicas e sociais, acabam por permanecer auxiliando os pais até a fase adulta. Para os profissionais de referência, a baixa escolaridade foi considerada uma barreira para a RP, pois um dos recursos oferecidos pelo Programa é a reabilitação em um novo cargo, por meio de cursos que exigem o ensino médio completo. A baixa escolaridade e a falta de preparo profissional da maioria dos trabalhadores, somadas às limitações funcionais decorrentes da doença, impõem uma realidade não promissora para o retorno ao trabalho e, consequentemente, para a autossuficiência econômica ${ }^{27}$. 
Embora alguns estudos tenham evidenciado que a baixa escolaridade, e a moradia distante da agência e em área rural sejam critérios para a inegibilidade $\mathbf{1 4 , 2 8}^{\mathbf{2 8}}$, neste estudo, os profissionais de referência citaram que alguns trabalhadores não tinham o perfil para a RP. Uma reflexão trazida por Cheres et al. ${ }^{\mathbf{2 8}}$ preconiza que a elegibilidade ao Programa demanda escolaridade, portanto, o encaminhamento de um trabalhador com baixa escolaridade ao Programa gera um descumprimento desse critério. Para os autores, este fato pode sinalizar que o INSS está buscando alternativa de inclusão de beneficiários com baixa escolaridade no Programa, visando à qualificação e ao retorno ao mercado de trabalho. Ou então, não há um alinhamento para os peritos quanto aos critérios para encaminhamento ao Programa. De qualquer forma, cabe refletir sobre os processos de exclusão de tais sujeitos, ao não serem considerados elegíveis ao Programa, e sobre os desafios existentes.

Outra barreira pontuada pelos entrevistados foi a dificuldade de deslocamento dos segurados (transporte), tanto para a agência do INSS quanto para os locais onde eram oferecidos os cursos de qualificação profissional, devido às características geográficas da região.

[...] Aqui mesmo, no Vale do Ribeira, por exemplo, tem as pessoas que, pra ir trabalhar, precisam passar por rio, precisam andar em estradas esburacadas [...] tem usuários, que têm problemas de coluna, que têm que andar quatro, cinco quilômetros pra chegar na pista, pra poder pegar a ambulância, ou então, para poder pegar o seu transporte. (João).

As dificuldades de transporte são comuns, e a distância de onde moram os trabalhadores de áreas rurais até os locais de tratamento dificulta a reabilitação'. Além disto, a RP tem sido realizada a partir do encaminhamento do segurado para cursos profissionalizantes de instituições parceiras do INSS, no entanto, muitas vezes esses cursos não são compatíveis com as habilidades, a escolaridade e os desejos dos segurados.
[...] os usuários que retornaram, relataram pra mim que, às vezes, forçavam ele a fazer um curso de logística, sendo que ele detesta trabalhar em logística; detesta trabalhar com separação, com envio de material... (João).

Essas situações, segundo os entrevistados, geravam sofrimento nos segurados, pois a oferta de cursos é restrita e poucos são gratuitos, o que dificultava suas escolhas e decisões.

[...] Aqui, como não tem convênios fortes, e os cursos não podem ser pagos, só podem ser gratuitos, por exemplo, o [Serviço Nacional de Aprendizagem Comercial] Senac, tem trocentos cursos, e aí, só tem bolsa 'nesse' e 'nesse', $e$, às vezes, o que ele (o segurado) quer fazer, é pago. (Marcos).

Essa incompatibilidade resultou em uma insatisfação do segurado e demonstrou a ineficácia da reabilitação como vem sendo feita, pois, de acordo com os relatos, não garantiu a reinserção nem a permanência no trabalho após o PRP, pois, o segurado realizava um curso no qual não tinha interesse/habilidade, ou não o capacitava para as necessidades do mercado. Para Vargas ${ }^{\mathbf{1 3}}$, a possibilidade de realização de cursos é fortemente limitada pelo nível de instrução do segurado e pela falta de apoio das empresas na reabilitação de seus empregados. Há pouca ou nenhuma interferência do Estado em relação ao cumprimento das restrições e orientações para o retorno do trabalhador ao trabalho. Há apenas o envio de ofícios relatando a incapacidade e solicitando a readaptação com ausência de ações presenciais ${ }^{26}$. Em um estudo, os trabalhadores perceberam que as empresas dificultavam o retorno, e que não havia preocupação em fazer reajustes no trabalho realizado anteriormente, nem a preocupação em definir um novo posto de trabalho para a recolocação ${ }^{\mathbf{1 8}}$.

Outra questão que surgiu pelas percepções dos entrevistados foi relacionada à avaliação do médico perito. 
[...] eles são vistos simplesmente com um foco centrado na doença e não ao ambiente ou nas questões que essa pessoa vive no ambiente. Não é entendido como é... os demais aspectos que influenciam essa vida da pessoa, né? (José).

[...] A gente vê um olhar muito medicocêntrico, muito centrado na doença, sem uma perspectiva de resolução do problema da pessoa. (Marcos).

A visão biomédica da incapacidade restringe-se aos aspectos físicos das lesões e do adoecimento. Considerando que a Classificação Internacional de Funcionalidade (CIF) ainda não foi normatizada como parâmetro no PRP, pelo INSS, o perito médico limita-se às normas previdenciárias vigentes, enfatizando suas análises na visão biomédica que privilegia os aspectos anatomotopatológicos ${ }^{28}$. $\mathrm{O}$ médico perito do INSS é o responsável pelo encaminhamento do trabalhador ao Programa, pela avaliação do potencial laborativo e pela decisão à alta no Programa. De acordo com o perfil de trabalhador da agência, apresentado pelos entrevistados, pareceu ser insuficiente utilizar somente a abordagem biomédica na avaliação do trabalhador. A perspectiva biomédica não abrange toda a complexidade envolvida na condição de saúde do segurado, pois não dá conta de responder sobre os aspectos sociais, culturais, políticos, econômicos e individuais envolvidos.

As dificuldades no processo de RP não impactavam na saúde mental apenas dos segurados, segundo os entrevistados, mas refletiam, negativamente, neles próprios.

\section{[...]. Você não consegue fazer uma reabilitação} decente, você não consegue tocar um programa profissional decente com o segurado. Ele vai cumprir as formalidades dentro da reabilitação profissional e vai ser jogado no mercado de trabalho numa condição que, muitas vezes, ele não consegue voltar para a atividade habitual, não consegue. E o curso que ele fez é curto e insuficiente. (Marcos).

Havia, frequentemente, um sentimento de impotência e frustração, pois não realizavam um trabalho que de fato atendesse às demandas e aos interesses apresentados pelos segurados no processo de RP, bem como, diante do contexto, era impossível atender ao objetivo do Programa, embora relatassem que se esforçavam ao máximo para garantir os direitos dos trabalhadores. E os profissionais, muitas vezes, não se sentiam exercendo seus papéis de assistentes sociais. A precarização do trabalho, com suas características de diluição das atribuições e competências específicas das profissões e a exigência de trabalhadores polivalentes, não deixa o assistente social de fora dessa realidade ${ }^{17}$.

Os profissionais de referência relataram, ainda, que constantemente havia um empenho em transformar as dificuldades e frustrações do trabalho, causadas pelas barreiras no processo de RP, em motivação e superação.

[...] me motiva a procurar saídas [...] você vai em busca, dentro das suas limitações, o que dá para você fazer. Aí, dentro do que dá para você fazer, eu procuro garantir o máximo de direito desse reabilitado. (Marcos).

Eram estratégias utilizadas para continuar a seguir em frente.

[...] essa frustação, a gente tenta transformar em motivação para a luta com esses nossos usuários, porque é uma frustação que você tem que simplesmente superar. Aí, como que eu vou superar essa frustação? É lutando para que isso se transforme, e lutar. (João).

Essas lutas em prol dos trabalhadores nem sempre ocorrem sem custos à saúde dos entrevistados. Existia o sentimento de culpa, de indignação e revolta, por sentirem que estavam 'favorecendo' o sistema, e, consequentemente, a exclusão social. $\mathrm{E}$ isto deve gerar, também entre os segurados, um sofrimento ético-político. Este sofrimento resulta na vivência cotidiana dos sujeitos nas situações sociais em que são tratados ou tratam o outro na 
intersubjetividade, como inferior, subalterno, sem valor, apêndice inútil da sociedade, e que é determinada pela organização social em um dado momento histórico ${ }^{29}$. Em um estudo com trabalhadores de Equipes de Saúde da Família, a principal causa desse sofrimento era a impotência para resolver o problema de saúde, tendo como pano de fundo um processo histórico-social mais amplo, relacionado com as políticas macroeconômicas de cunho neoliberal ${ }^{30}$.

Embora cada profissão tenha seu projeto profissional, no caso dos assistentes sociais, existe um projeto ético-político, que expressa os anseios e valores destes profissionais, que podem entrar em contato com determinada realidade institucional, que, na maioria das vezes, pode não estar na mesma direção da própria profissão, gerando a necessidade de enfrentamento de um conjunto de relações entre as forças políticas e econômicas e a subordinação aos processos de trabalho impostos ${ }^{30}$.

\section{Facilitadores e os desafios no proces- so de RP}

Apesar das barreiras encontradas, os entrevistados relataram situações e condutas por eles tomadas que podem ser consideradas como facilitadoras no processo de RP dos segurados. A visão mais abrangente e empática a respeito da realidade de vida do segurado por parte dos profissionais de referência - no caso, assistentes sociais - possibilitou, em alguns momentos, o enfrentamento de situações adversas e conflitantes, promovendo diálogos abertos com os segurados sobre suas realidades e necessidades.

[...] se eu não dialogo com esse usuário, se eu simplesmente imponho as coisas que têm que ser feitas, sem discutir com ele, sem perceber as dificuldades, sem estar automaticamente respeitando a própria vida dele, a gente vai ter uma relação difícil, conflituosa; uma relação em que ele não vai ter confiança, e não vai ter vinculação comigo. (João).
Segundo Prado e Duarte ${ }^{31}$, o INSS adota o modelo de gestão baseado na racionalização do trabalho, e todo o processo de trabalho é controlado institucionalmente, e hierarquizado ao máximo, atribuindo aos profissionais meras funções executivas. De acordo com os relatos, para que, de fato, houvesse uma possibilidade de sucesso no Programa, eram necessárias ações e atitudes do profissional de referência, que não eram previstas no rol de procedimentos técnicos e, portanto, partiam da iniciativa própria deste. De acordo com os depoimentos das entrevistas, os PR mencionaram a necessidade de atuação com 'algo a mais', que deveria ser adicionado ao atendimento e que facilitava a relação com os segurados.

Essa forma de relação é possível quando se tem empatia e uma compreensão da história de vida e das dificuldades enfrentadas pelo outro:

[...]. Eu tenho uma filha. Me imagino na situação dessa pessoa, né?, e fico pensando. Me revolto um pouco, mais no sentido da empatia da situação da pessoa, e me desperto um pouco, de inquietude, de movimentação e de busca. (Marcos).

$\mathrm{O}$ apoio, as relações e as atitudes individuais oferecidas pelos profissionais do INSS, bem como o acolhimento e o reconhecimento do sofrimento presente no processo saúde-doença-trabalho são fatores que facilitam o retorno ao trabalho ${ }^{32}$. Entre os principais facilitadores, de acordo com um estudo sobre trabalhadores afastados do trabalho atendidos em um Centro de Referência em Saúde do Trabalhador, identificou-se que o principal facilitador para o retorno ao trabalho está no apoio, nos relacionamentos e nas atitudes individuais oferecidos pelos profissionais de tal serviço ${ }^{26}$.

A importância da equipe multiprofissional e de diferentes 'visões' sobre os casos também foi ressaltada.

[...] A gente tem que ter um olhar diferenciado com relação às relações que esse usuário traz. A gente tem que ter um olhar diferenciado com relação ao acesso que esse usuário tem. (João). 
Essa diferença diz respeito à visão sobre outros aspectos envolvidos na doença, como os aspectos biopsicossociais. De acordo com os profissionais de referência, uma avaliação que levasse em conta todos os aspectos envolvidos no processo saúde-doença permitiria um melhor encaminhamento aos cursos profissionalizantes, com possíveis indicações de realocação em outros postos de trabalho.

Essa visão ampliada sobre a multifatorialidade que envolve o processo saúde-doença, o afastamento e o retorno ao trabalho, vai de encontro ao próprio perfil profissional, às competências e aos valores do assistente social. Um dos aspectos envolvidos neste processo, e que é um dos focos destes profissionais, diz respeito às redes de apoio social. Por exemplo, a família, que pode ser também fundamental nesse processo de retorno ao trabalho.

[...] algumas pessoas (familiares), inclusive, questionam aos segurados: 'Você está em auxílio-doença, e por que você fica tanto tempo de casa?'. Então, é trazer também essas pessoas, esses familiares para estar conversando com eles, explicando para eles como é que se dá o procedimento de reabilitação. (Marcos).

De acordo com os relatos, houve a necessidade de lidar com as redes de apoio, incluindo a família, pois os segurados se deparavam muitas vezes com situações de discriminação junto aos familiares e nos serviços de saúde, por estarem em situação de afastamento do trabalho. Os profissionais de referência mencionaram a importância de haver essas redes de apoio, sempre que possível, visto que não eram uma prioridade para o Programa. Trabalhadores adoecidos, ao conviverem com situações de incapacidade e sofrimento, costumam encontrar na família meios de enfrentar as situações ${ }^{32}$.

Porém, há grandes desafios existentes para a realocação de sujeitos em postos de trabalho após o afastamento por motivo de doença, decorrente do descaso dos empregadores e de ausência de políticas públicas efetivas que favoreçam esse retorno, especialmente em áreas rurais. Ainda, o estabelecimento de metas entre as partes interessadas no processo de retorno ao trabalho - sejam trabalhadores, empregadores, profissionais de saúde, prestadores de serviços, contribuintes e/ou sociedade - deve ser sustentado por ações sociais combinadas entre os atores sociais envolvidos na reabilitação ${ }^{31}$.

\section{Considerações finais}

De acordo com os dados obtidos na primeira etapa, os trabalhadores rurais atuavam com ênfase na bananicultura, moravam nas fazendas dos empregadores, a maioria tinha baixa escolaridade, e todos refeririam sintomas osteomusculares no trabalho. Apresentaram dificuldades de acesso aos serviços de saúde e preferência por automedicação e medicamentos caseiros. O perfil de trabalhadores rurais encontrado em uma região trouxe algumas informações que complementaram e/ou informaram alguns dados obtidos junto aos profissionais de referência da região estudada, porém o estudo sofreu limitações por apresentar dados de trabalhadores de apenas um território do município de Registro (SP), e de sujeitos não vinculados ao PRP.

Em relação às entrevistas, entre as principais barreiras encontradas estiveram: o perfil dos segurados da região, de serem moradores de área rural, trabalhadores 'braçais', de baixa escolaridade; a avaliação do médico perito com base no modelo biomédico; e a incompatibilidade de cursos oferecidos com o perfil dos segurados. Além disto, os critérios de inelegibilidade ao PRP são compatíveis com o perfil da população atendida por essa agência, o que demonstra que o atual modelo de RP é incompatível com as demandas da população rural. Outra questão importante identificada foi o possível impacto negativo da RP na saúde mental dos profissionais de referência, visto que eles se sentiam frustrados e impotentes em relação aos resultados de seus trabalhos, com aspectos que devem ser aprofundados em 
estudos futuros. Muitas vezes, eles se culpabilizaram por julgarem realizar maus serviços e serem instrumentos de violação dos direitos sociais. Quanto aos facilitadores, tiveram relação com as atitudes dos profissionais de referência frente às dificuldades dos segurados que atendiam, entre elas, o acolhimento, o vínculo e a empatia, que foram aspectos que os profissionais de referência mencionaram por perceberem que melhoravam a relação entre segurado e profissional, e estabeleciam confiança e respeito entre eles, o que facilitava o processo de RP.

A reforma da previdência implicará na redução de acesso aos benefícios sociais em proporções ainda desconhecidas, porém preocupantes. Certamente, limitará o acesso aos benefícios previdenciários dos trabalhadores rurais, e, portanto, é de extrema necessidade trazer à luz reflexões sobre a população aqui estudada.

Há a necessidade de melhorias no modelo de RP dos trabalhadores rurais, para que sejam compatíveis com as suas necessidades e características, bem como de uma política pública que assegure, de fato, os direitos trabalhistas, de promoção à saúde e a segurança no trabalho, visto que eles estão expostos a condições inadequadas de trabalho e a vínculos trabalhistas frágeis.

Este estudo teve limitações na primeira etapa, pela seleção de apenas alguns bairros rurais, e por terem sido investigado apenas alguns dados do perfil sociodemográfico, e, em relação à saúde, por ter sido observada apenas a presença ou não de sintomas osteomusculares. Também houve limitações em relação à baixa amostra de entrevistados $(n=2)$, por referir-se a uma única agência, não sendo possível fazer generalização dos dados obtidos. Porém, há poucos estudos sobre a RP em áreas rurais, e espera-se que futuros estudos possam aprofundar tais debates.

\section{Colaboradores}

Zavarizzi CP (0000-0002-4143-0192)* contribuiu para a análise e interpretação dos dados, revisão crítica do conteúdo; e aprovação da versão final do manuscrito. Simas JMM (00000003-1742-3707)* contribuiu para a concepção dos dados; revisão crítica do conteúdo; e aprovação da versão final do manuscrito. Santos LF (0000-0003-2923-4962)* contribuiu para a concepção, planejamento e interpretação dos dados; elaboração do rascunho; e aprovação da versão final do manuscrito. Alencar MCB (0000-0001-7555-4153)* contribuiu para a análise e interpretação dos dados; elaboração do rascunho e revisão crítica do conteúdo; e aprovação da versão final do manuscrito. 


\section{Referências}

1. Schlindwein VLDC. A desproteção social dos trabalhadores rurais nos acidentes de trabalho. Textos Context. 2011; 10(1):109-117.

2. Instituto Brasileiro de Geografia e Estatística. Censo demográfico populacional. Rio de Janeiro: IBGE; 2010. 2003 p.

3. Instituto Brasileiro de Geografia e Estatística. Censo Agro 2017. Rio de Janeiro: IBGE; 2018.

4. Ximenes Neto FRG, Aurélio DO, Santos FD, et al. Perfil Sociodemográfico e Trabalhista dos Trabalhadores Rurais Vítimas de Acidente no Semiárido Cearense. Enferm. Foco. 2016; 7(1):56-60.

5. Brasil. Constituição, 1988. Constituição da República Federativa do Brasil. Brasília, DF: Senado Federal; 1988.

6. Pinto NF, Murofuse NT, Carvalho M. Processo e cargas de trabalho e a saúde dos trabalhadores na sericicultura: uma revisão. Rev. Bras. Saúde Ocup. 2015; 40(132):237-247.

7. Martins AJ, Ferreira NS. Ergonomia no trabalho rural. Rev. Eletrôn. Atualiza Saúde. 2016; 2(2):125-134.

8. Das B. Agricultural work related injuries among farmers of West Bengal, India. Int. J. Inj. Contr. Saf. Promot. 2014; 21(3):205-215.

9. Menegat RP, Fontana RT. Condições de trabalho do trabalhador rural e sua interface com o risco de adoecimento. Ciênc. Cuid. Saúde. 2010; 9(1):52-59.

10. Carneiro FF, Rigotto RM, Augusto LGS, et al. Dossiê ABRASCO: um alerta sobre os impactos dos agrotóxicos na saúde. [internet]. Rio de Janeiro: EPSJV; 2015. [acesso em 2020 jan 6]. Disponível em: http:// abrasco.org.br/dossieagrotoxicos/.

11. Brasil. Lei no 8.213 , de 24 de julho de 1991. Dispõe sobre os Planos de Benefícios da Previdência Social e dá outras providências. Diário Oficial da União. 25 Jul 1991.

12. Iguti AM. As mudanças nas práticas de reabilitação profissional da Previdência Social no Brasil: modernização ou enfraquecimento da proteção social? Cad. Saúde Pública. 2008; 24(11):2661-2670.

13. Vargas AC, Santos ACT, Souza RM, et al. Percepção dos usuários a respeito de um serviço de reabilitação profissional. Rev. Bras. Saúde Ocup. 2017; 42(11):1-10.

14. Santos GSH, Lopes RE. A (in)elegibilidade de trabalhadores encaminhados ao Programa de Reabilitação Profissional do INSS. Rev. Katálysis. 2016; 18(2):15161.

15. Brasil. Ministério da Previdência Social. Manual técnico de procedimentos da área de reabilitação profissional. Brasília, DF: Ministério da Previdência Social; 2018

16. Miranda CB. Aspectos do cenário atual da reabilitação profissional no Brasil: avanços e retrocessos. Cad. Saúde Pública. 2018;34(8):1-14.

17. Pereira MCC, Nogueira CM. Serviço Social e reabilitação profissional do Instituto Nacional do Seguro Social: perspectivas a partir da saúde do trabalhador. In: Anais do VIII Seminário de Saúde do Trabalhador; 2012 Set 25-27; São Paulo. São Paulo: UNESP; 2012. p. 1-10.

18. Cestari E, Carlotto MS. Reabilitação profissional: o que pensa o trabalhador sobre sua reinserção. Estud. Pesqui. Psicol. 2012; 12(1):93-115.

19. Poersch AL, Merlo RC, Muitas R, et al. Reabilitação profissional e retorno ao trabalho: uma aposta de intervenção. Psicol. Soc. 2017; (29):1-10.

20. Maeno M, Vilela RAG. Reabilitação profissional no Brasil: elementos para a construção de uma política pública. Rev. Bras. Saúde Ocup. 2010; 35(121):87-99. 
21. Governo de São Paulo. Vale do Ribeira abrange 31 cidades nos estados de SP e PR [internet]. São Paulo: Governo de São Paulo; 2018. [acesso em 2020 jan 6]. Disponível em: http://www.saopaulo.sp.gov.br/spnoticias/vale-do-ribeira-dois-estados/.

22. Bardin L. Análise de conteúdo. Lisboa: Edições 70; 2010.

23. Bastos RC, Bifano ACS. "Estado da arte" sobre as publicações científicas envolvendo o trabalho agrícola familiar no brasil sob o ponto de vista ergonômico. Rev. Eng. na Agric. 2017; 25(1):27-37.

24. Brasil. Ministério da Saúde. Política Nacional de Saúde Integral das Populações do Campo e da Floresta. Brasília (DF): Ministério da Saúde; 2013.

25. Martins AJ, Ferreira NS. A ergonomia no trabalho rural. Rev. Eletrôn. Atualiza Saúde. 2015; 2(2):125-134.

26. Houvet P, Obert L. Upper limb cumulative trauma disorders for the orthopaedic surgeon. Orthop. Traumatol. Surg. Res. 2013; 99(1):104-114.

27. Toldrá RC, Daldon MTB, Santos MC, et al. Facilitadores e barreiras para o retorno ao trabalho: a experiência de trabalhadores atendidos em um centro de referência em saúde do trabalhador - SP, Brasil. Rev. Bras. Saúde Ocup. 2010; 35(121):10-22.

28. Cheres JEC, Almeida GR, Carvalho J, et al. Reabilitação Profissional na Agência da Previdência Social do Município de Timóteo: Uma Prática Possível? Rev.

Eletrônica Ciências Jurídicas. 2014; 1(4):1-12.

29. Sawaia B. Sofrimento ético-político como categoria de análise da dialética exclusão/inclusão. In: Sawaia B, organizador. As artimanhas da exclusão: análise psicossocial e ética da desigualdade social. Petrópolis: Vozes; 2001. p. 97-118.

30. Curvo DR. O Sofrimento Ético-Político e a Reforma Sanitária Brasileira: Algumas Considerações Sobre os Trabalhadores de uma Unidade de Saúde da Família. R. Bras. Ci. Saúde. 2012; 15(3):295-308.

31. Prado FO, Duarte EEC. A racionalização do trabalho dos assistentes sociais do INSS. Rev Katálysis. 2015; 18(2):162-171.

32. Saldanha JHS, Pereira APM, Neves RF, et al. Facilitadores e barreiras de retorno ao trabalho de trabalhadores acometidos por LER/DORT. Rev. Bras. Saúde Ocup. 2013; 38(127):122-138.

33. Pestana BM, Valença JBM, Graeser AEM, et al. O retorno ao trabalho de sujeitos acometidos por LER/ DORT. Cad. Bras. Ter. Ocup. 2017; 25(4):735-742.

Recebido em 16/06/2019

Aprovado em 16/10/2019

Conflito de interesses: inexistente

Suporte financeiro: não houve 